\section{BRAZIULIAN JOURNAL}

OF MEDICAL AND BIOLOGICAL RESFARCH

www.bjournal.com.br
ISSN 0100-879X

Volume 43 (8) 698-811 August 2010

BIOMEDICAL SCIENCES

AND

CLINICAL INVESTIGATION

Braz J Med Biol Res, August 2010, Volume 43(8) 728-736

doi: 10.1590/S0100-879X2010007500066

Interaction between growth differentiation factor 9, insulin-like growth factor I and growth hormone on the in vitro development and survival of goat preantral follicles

F.S. Martins, J.J.H. Celestino, M.V.A. Saraiva, R.N. Chaves, R. Rossetto, C.M.G. Silva, I.B. Lima-Verde, C.A.P. Lopes, C.C. Campello and J.R. Figueiredo

The Brazilian Journal of Medical and Biological Research is partially financed by

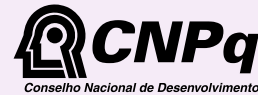

Ministério da Ciência e Tecnologia

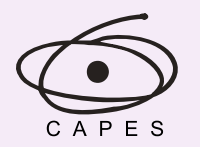

Ministério da Educação

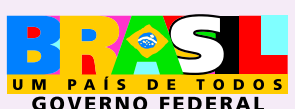

GOVERNO FEDERAL

\section{FAPESP}

Institutional S ponsors

Hotsite of proteomics metabolomics developped by:

$$
\text { an }
$$




\title{
Interaction between growth differentiation factor 9, insulin-like growth factor I and growth hormone on the in vitro development and survival of goat preantral follicles
}

\author{
F.S. Martins, J.J.H. Celestino, M.V.A. Saraiva, R.N. Chaves, R. Rossetto, \\ C.M.G. Silva, I.B. Lima-Verde, C.A.P. Lopes, C.C. Campello and J.R. Figueiredo \\ Laboratório de Manipulação de Oócitos e Folículos Ovarianos Pré-antrais, Faculdade de Veterinária, \\ Universidade Estadual do Ceará, Fortaleza, CE, Brasil
}

\begin{abstract}
The objective of this study was to determine the effects of GDF-9, IGF-I, and GH alone or combined on preantral follicle survival, activation and development after 1 and 7 days of in vitro culture. Either fresh (non-cultured) or cultured ovarian tissue was processed for histological and fluorescence analysis. For all media tested, the percent of normal follicles was greater when compared to minimum essential medium supplemented $\left(\mathrm{MEM}^{+}\right)$alone, except when ovarian tissue was cultured with GDF-9/ IGF-I or GDF-9/GH (P < 0.05). Fluorescence analysis showed that the percent of viable follicles after 7 days of culture was similar for non-cultured tissue and for all treatments tested. The percent of primordial follicles was reduced $(P<0.05)$ and there was a significant and concomitant increase in the percent of intermediate and primary follicles in all treatments tested after 7 days of culture when compared to non-cultured tissue. After 7 days of culture, the highest percent of intermediate follicles was observed with IGF-I/GH (61.3\%), and the highest percent of primary follicles was achieved with IGF-I (57.7\%). After 7 days of culture in $\mathrm{MEM}^{+}$containing GDF-9, IGF-I and GH alone or in all associations, a significant increase in follicular diameter was observed when compared to $\mathrm{MEM}^{+}$alone and non-cultured tissue. In conclusion, GDF-9, IGF-I and GH alone or in combination maintain preantral follicle survival and promote primordial follicle activation. Nevertheless, the data showed that IGF-I/GH and IGF-I alone are efficient in promoting the transition from primordial to intermediate follicles and from intermediate to primary follicles, respectively.
\end{abstract}

Key words: GDF-9; IGF-I; GH; Culture; Follicle activation; Goat

\section{Introduction}

It is necessary to develop culture strategies that support the activation and sustained in vitro growth of primordial follicles in order to maximize the reproductive potential of ovarian tissue (1). Progress in culture systems that can support growth and development of preantral follicles in domestic species has been slow when compared with mice, for which complete growth can be achieved, resulting in the production of live mice (2).

Although the mechanisms regulating the activation and subsequent growth of primordial follicles remain poorly understood, accumulating evidence indicates that follicular development depends on the presence of oocyte/granulosa cell interactions and on the secretion of a range of local factors, e.g., growth differentiation factor 9 (GDF-9), bone morphogenetic proteins, activin, inhibins, basic fibroblast growth factor, insulin-like growth factor I (IGF-I), and epidermal growth factor (3). GDF-9 has been located in the oocytes of mice $(4,5)$ and rats $(6)$, and in human (7) primary follicles. Nilsson and Skinner (8) have shown that GDF-9 promotes the development of primary follicles in neonatal rat ovaries. Furthermore, recent studies have shown that GDF-9 stimulates the in vitro growth of preantral follicles and thecal cell differentiation in the rat $(5,9)$ as well as primary and early secondary follicle formation in human ovarian slices in vitro (10). Recently, we have demonstrated that GDF-9 promotes in vitro follicular survival, growth and progression

Correspondence: F.S. Martins, R. Dr. Alfredo Weyne, 55/103-C, 60415-520 Fortaleza, CE, Brasil.

E-mail: fabricio@netbandalarga.com.br

Received December 13, 2009. Accepted June 18, 2010. Available online July 15, 2010. Published August $13,2010$. 
to the secondary follicle stage in goats, maintaining follicular ultrastructure (11). There is a growing body of evidence showing that IGF-I plays a key role in the development of preantral follicles and in the process of follicular atresia. When added during in vitro culture of preantral follicles, IGF-I has been shown to stimulate follicular growth in humans (12), cattle (13), rats (14), and mice (15) in synergy with follicle-stimulating hormone. In the rat, IGF-I added during in vitro preantral follicular culture significantly increased follicular diameter and DNA content (14). For secondary follicle growth, supplementation of culture medium with IGF-I effectively maintained oocyte survival and stimulated the growth of goat follicles cultured in vitro (16). The development of preantral follicles has generally been considered to be largely independent of gonadotrophins and pituitary hormones. However, increasing evidence indicates that growth hormone $(\mathrm{GH})$, in addition to having metabolic effects, is involved in the regulation of ovarian functions, including the preantral stage of development $(14,17)$. In vitro studies in immature mice showed a stimulatory effect of $\mathrm{GH}$ on preantral follicle development and follicular cell proliferation that is synergistic with IGF-I $(15,18,19)$. GH may thus be particularly important in the recruitment of follicles and the initiation of oocyte growth, perhaps by adjusting nutritional status to the number of growing oocytes (20). Furthermore, $\mathrm{GH}$ has been shown to enhance cell proliferation and steroidogenesis of cultured granulosa cells in rats (21) and in cattle (22), pointing out an important role of this hormone in the regulation of follicular growth. Early studies assumed that IGF-I was the sole mediator of $\mathrm{GH}$ action in the ovary, since IGF-I or GH enhances steroid production to the same extent in rats (23) and GH usually increases follicular-luteal IGF-I in cows (24). Although some actions of GDF-9, GH and IGF-I on ovaries have been well analyzed in some mammalian species, little is known about their interaction on the development of goat preantral follicles. The present study was designed to investigate the possible effect of the interaction of GDF-9, IGF-I and GH on the survival, activation and growth of goat preantral follicles cultured in vitro.

\section{Material and Methods}

\section{Chemicals \\ GDF-9, GH and IGF-I were purchased from Cell Science (USA) and, unless otherwise mentioned, culture media and chemicals used in the present study were purchased from Sigma Chemical Co. (USA). \\ In vitro culture of ovarian tissue and morphological evaluation}

Ovaries $(N=12)$ from 6 adult ( $1-3$ years old), nonpregnant mixed-breed goats were collected at a local slaughterhouse. The animals were cycling and in good body condition. Immediately after the death of the animals, the ovaries were washed in $70 \%$ alcohol followed by two washes in minimum essential medium (MEM). The pair of ovaries from each animal was transported to the laboratory in $20 \mathrm{~mL}$ MEM- $\alpha$ supplemented with HEPES, penicillin (100 $\mu \mathrm{g} / \mathrm{mL})$ and streptomycin $(100 \mu \mathrm{g} / \mathrm{mL})$ within $1 \mathrm{~h}$, at $4^{\circ} \mathrm{C}$. In the laboratory, the ovaries from each animal were stripped of surrounding fat tissue and ligaments. The ovarian cortex of each pair of ovaries was then divided into 17 fragments measuring approximately $3 \times 3$ and $1 \mathrm{~mm}$ thick using a needle and scalpel under sterile conditions. One fragment was taken randomly and immediately fixed for histological examination (control). The 16 remaining fragments were placed individually in 24-well culture dishes, each well containing $1 \mathrm{~mL}$ culture medium. The medium used was MEM- $\alpha$ (osmolarity 300 mOsm/L, pH 7.2; Gibco, USA) supplemented with ITS $(6.25 \mu \mathrm{g} / \mathrm{mL}$ insulin, $6.25 \mu \mathrm{g} / \mathrm{mL}$ transferrin, and $6.25 \mathrm{ng} / \mathrm{mL}$ selenium), $2 \mathrm{mM}$ glutamine, 2 $\mathrm{mM}$ hypoxanthine, and $1.25 \mathrm{mg} / \mathrm{mL} \mathrm{BSA}$, which is denoted $\mathrm{MEM}^{+}$. The ovarian cortex fragments were cultured for 1 or 7 days at $39^{\circ} \mathrm{C}$ in humidified air with $5 \% \mathrm{CO}_{2}$ in $\mathrm{MEM}^{+}$ alone or MEM ${ }^{+}$plus GDF-9 $(200 \mathrm{ng} / \mathrm{mL})$, IGF-I $(50 \mathrm{ng} / \mathrm{mL})$, or $\mathrm{GH}(10 \mathrm{ng} / \mathrm{mL})$ alone or in combination (GDF-9 + IGF-I, GDF-9 + GH, IGF-I + GH, or GDF-9 + IGF-I + GH. Each treatment was repeated six times and the culture medium was changed every 2 days.

\section{Morphological analysis and assessment of in vitro follicular growth}

Immediately after fragmentation, pieces of ovarian cortex were immersion-fixed for $12 \mathrm{~h}$ in $10 \%$ neutral buffered formaldehyde, $\mathrm{pH}$ 6.8-7.2, to serve as non-cultured control (fresh control). After 1 or 7 days of culture in each medium, the pieces of ovarian cortex were fixed as described above, dehydrated in a graded ethanol series, clarified with xylene, and embedded in paraffin. The samples were sectioned (7- $\mu \mathrm{m}$ thick), mounted on charged slides and allowed to dry overnight at $37^{\circ} \mathrm{C}$ before staining with periodic acid Schiff and hematoxylin. Follicle stage and survival were assessed microscopically on serial sections. Coded slides were examined under a Nikon microscope (Japan) at 400X magnification with the code unknown to the observer.

The developmental stages of follicles have been defined as primordial (oocyte surrounded by a few flattened granulosa cells) or developing, i.e., intermediate (oocyte surrounded by flattened and at least one cuboidal granulosa cell), primary (oocyte surrounded by a complete layer of cuboidal granulosa cells), or secondary (oocyte surrounded by two or more complete layers of cuboidal granulosa cells). Primordial and developing follicles were classified as morphologically normal (follicles containing an intact oocyte and granulosa cells well-organized in layers without a pyknotic nucleus) and degenerated follicles (oocyte with a pyknotic nucleus, retracted cytoplasm or disorganized granulosa cells detached from the basement membrane), as described by Silva et al. (25). 
The percent of primordial and developing follicles was calculated on day 0 (control) and after 1 or 7 days of culture in each medium. Overall, 180 follicles were evaluated for each treatment ( 30 follicles per treatment in one repetition $x$ 6 repetitions $=180$ follicles). In addition, follicular diameter was measured using only normal follicles from day 0 and after culture. Follicle diameter was recorded from edge to edge of granulosa cell membrane, or from the outside edge of the theca cell layer when present. Oocyte diameter was recorded from edge to edge of the oocyte membrane. Two perpendicular diameters were recorded for each and the average of these two values was reported as follicle and oocyte diameter, respectively. It is important to note that only follicles with a visible oocyte nucleus were evaluated to avoid double counting.

\section{Assessment of preantral follicle viability by fluorescence microscopy}

The viability of the follicles cultured in $\mathrm{MEM}^{+}$alone or in $\mathrm{MEM}^{+}$with different combinations of GDF-9, IGF-I and $\mathrm{GH}$ was further analyzed using a more accurate method of assessment based on fluorescent probes. Pairs of ovaries $(\mathrm{N}=4)$ were cut into fragments, one of which was immediately processed for follicle isolation (non-cultured tissue). The remaining fragments were cultured in vitro and then submitted to isolation and analysis.

Goat preantral follicles were isolated from ovarian fragments using the mechanical method described by Lucci et al. (26). Briefly, with a tissue chopper (The Mickle Laboratory Engineering Co., UK) adjusted to a sectioning interval of $75 \mu \mathrm{m}$, samples were cut into small pieces, which were placed in MEM, resuspended 40 times using a large Pasteur pipette (diameter of about $1600 \mu \mathrm{m}$ ), and subsequently resuspended 40 times with a smaller Pasteur pipette (diameter of approximately $600 \mu \mathrm{m}$ ) to dissociate preantral follicles from the stroma. The material thus obtained was passed through 100- $\mu \mathrm{m}$ nylon mesh filters, resulting in a suspension containing preantral follicles smaller than 100 $\mu \mathrm{m}$ in diameter. This procedure was carried out within 10 min at room temperature.

Preantral follicles were analyzed using a two-color fluorescence cell viability assay based on the simultaneous determination of live and dead cells with calcein-AM and ethidium homodimer-1, respectively. While the first probe detected intracellular esterase activity of viable cells, the latter labeled nucleic acids of non-viable cells with plasma membrane disruption. The test was performed by adding 4 $\mu \mathrm{M}$ calcein-AM and $2 \mu \mathrm{M}$ ethidium homodimer-1 (Molecular Probes, Invitrogen, Germany) to the suspension of isolated follicles, followed by incubation at $37^{\circ} \mathrm{C}$ for $15 \mathrm{~min}$. After labeling, follicles were washed once by centrifugation at $100 \mathrm{~g}$ for $5 \mathrm{~min}$ and resuspension in MEM, mounted on a glass microscope slide in $5 \mu \mathrm{L}$ antifading medium (DABCO, Sigma, Germany) to prevent photobleaching, and finally examined using a TI fluorescence microscope (Nikon) equipped with a custom Nikon DS-U1 color camera. Digital images were acquired with the Lasersharp 2000 software under Windows XP. The emitted fluorescent signals of calcein-AM and ethidium homodimer-1 were collected at 488 and $568 \mathrm{~nm}$, respectively. Oocytes and granulosa cells were considered to be live if the cytoplasm stained positively with calcein-AM (green) and if chromatin was not labeled with ethidium homodimer-1 (red).

\section{Statistical analysis}

Kolmogorov-Smirnov and Bartlett tests were applied to confirm normal distributions and homogeneity of variance, respectively. Analysis of variance was then performed using the GLM procedure of SAS (1999) and the Dunnett test was applied for comparison of control groups against each treatment tested (27), while the SNK test was used to compare different treatments and days of culture. Data are reported as means $\pm S D$, and the level of significance was set at $P<0.05$ for all analyses.

\section{Results}

\section{Effect of GDF-9, IGF-I and GH on the in vitro survival of preantral follicles}

Histological analysis showed the presence of degenerated (Figure 1A) and normal (Figure 1B) follicles in cultured ovarian cortical fragments. In degenerated follicles, shrunken oocytes with a pyknotic nucleus or disorganized granulosa cells were observed. A total of 1950 follicles were counted to evaluate follicular morphology, activation and growth. Figure 2 shows the percent of normal follicles in non-cultured (day 0 , fresh control) ovarian cortical pieces and after 1 or 7 days of culture in different media. After 7 days, the percent of normal follicles cultured with GDF-9 was similar $(P>0.05)$ to that observed in non-cultured tissue $(82.66 \%)$, indicating the importance of this factor for the maintenance of follicular survival.

After 7 days of culture, the percent of histologically normal follicles in all media tested was higher $(P<0.05)$ when compared to $\mathrm{MEM}^{+}$, except when the ovarian cortex was cultured with GDF/IGF and GDF/GH. Moreover, after 7 days, the number of normal follicles observed with GDF/ IGF (44\%) and GDF/GH (40\%) showed the lowest percent compared with other media tested $(P<0.05)$. The increase of the culture period from 1 to 7 days reduced $(P<0.05)$ the percent of intact follicles in all media tested, except in tissues cultured in IGF/GH.

\section{Assessment of follicle viability after culture}

Based on the results of morphological evaluation, goat preantral follicles were isolated from fresh control and ovarian fragments cultured for 7 days with $\mathrm{MEM}^{+}$or $\mathrm{MEM}^{+}$ plus GDF-9, IGF-I and GH, each alone or in different combinations. A viability assay was performed using isolated follicles from fresh and cultured ovarian fragments from all 
treatments. A fluorescence cell viability assay based on the labeling of live and dead cells by calcein-AM and ethidium homodimer-1, respectively, was employed. Viable and nonviable preantral follicles after in vitro culture are shown in Figure 3. The percent of viable follicles after seven days of culture was similar for $\mathrm{MEM}^{+}$and all treatments tested (Table 1).

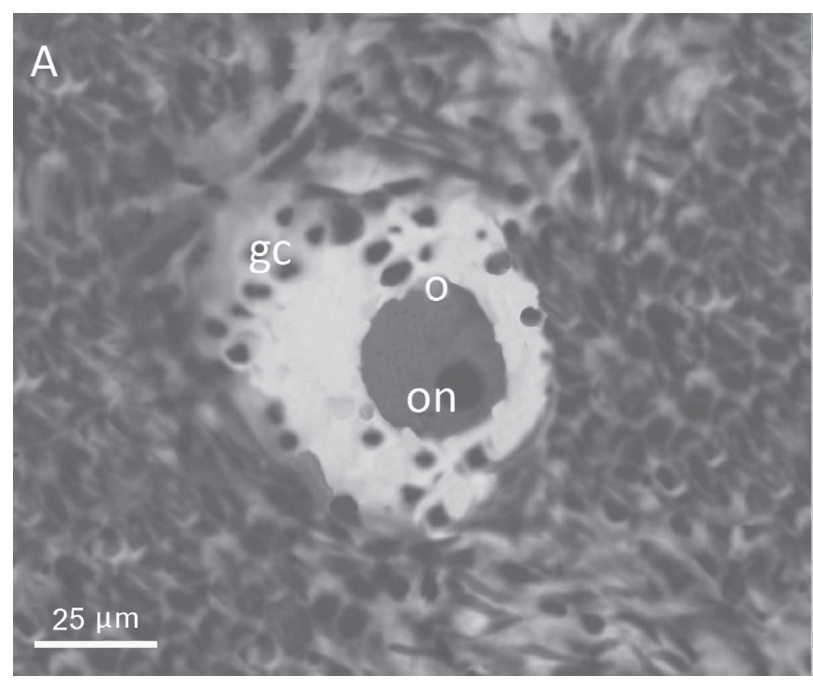

\section{Goat primordial follicle activation and growth during in vitro culture}

In fresh tissue, the percentages of primordial, intermediate and primary follicles were $72.7,21.2$, and $5.34 \%$, respectively. After 1 and 7 days of culture, the percent of primordial follicles (Figure 4A, $\mathrm{P}<0.05$ ) was significantly decreased in all media tested compared to non-cultured

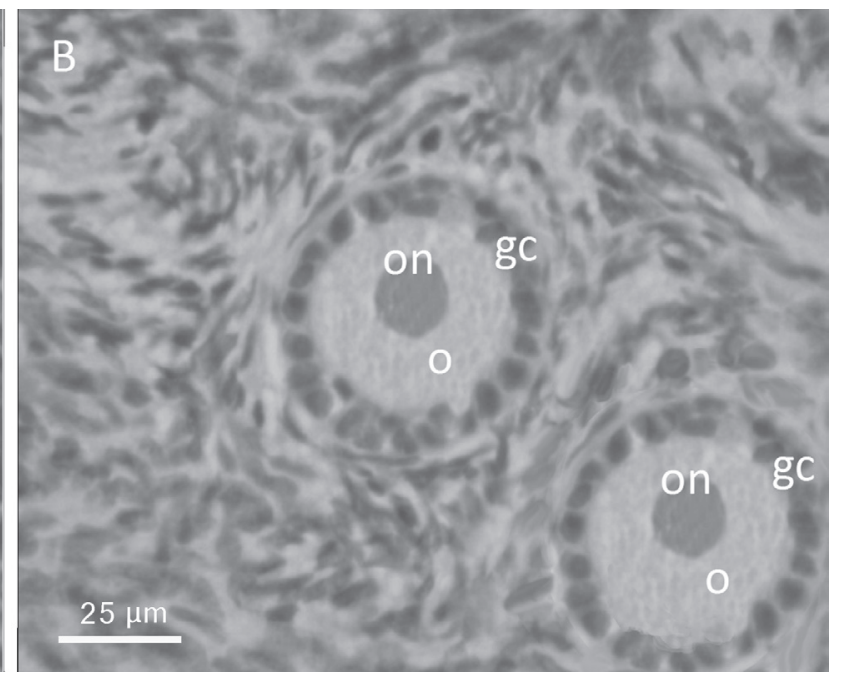

Figure 1. Degenerated primary follicles $(A)$ and normal primary follicles (B) after 7 days of culture with $50 \mathrm{ng} / \mathrm{mL}$ IGF-I. Sections were stained with periodic acid-Schiff-hematoxylin. $\mathrm{o}=$ oocyte; on = oocyte nucleus; gc = granulosa cells (original magnification 400X).

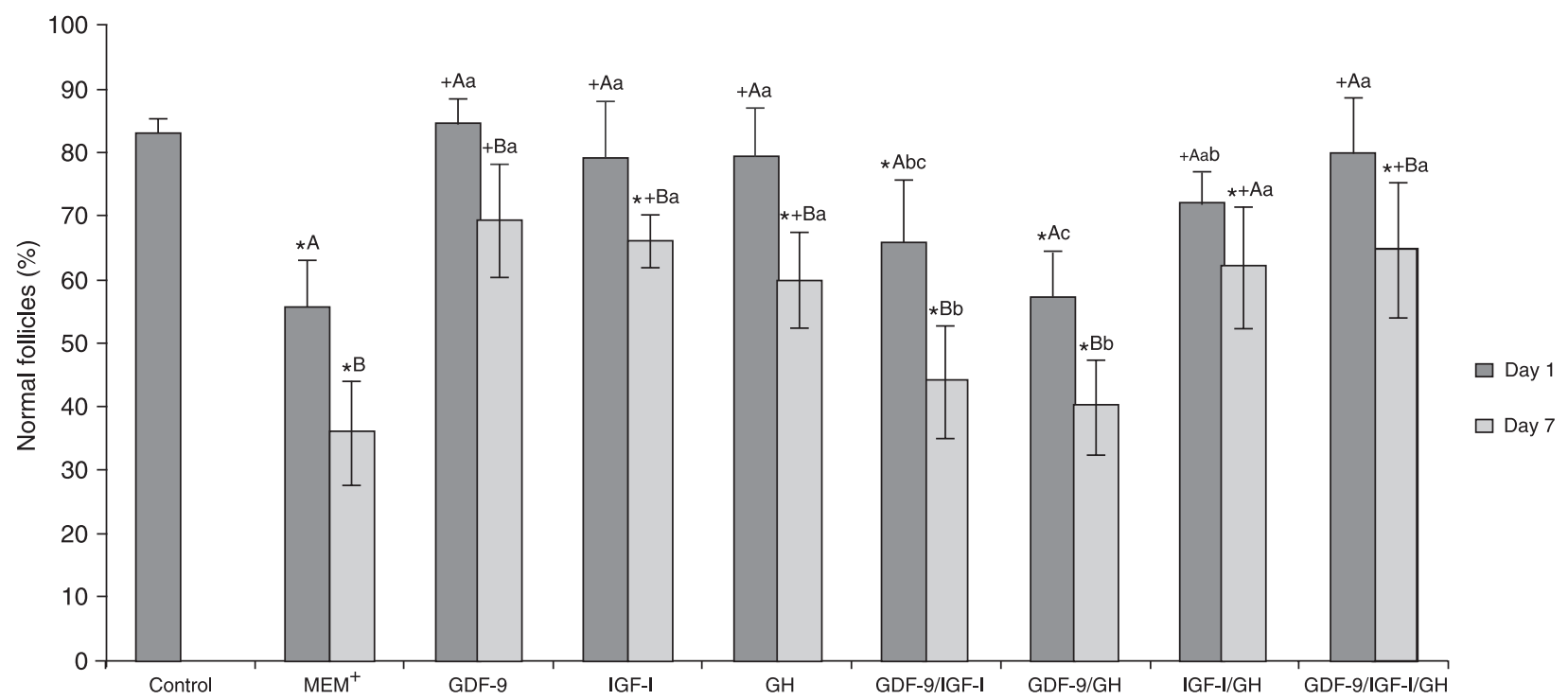

Figure 2. Percent of normal follicles in non-cultured tissue and in tissue after culture for 1 or 7 days in MEM ${ }^{+}, \mathrm{MEM}^{+}$plus GDF-9, IGF-I and GH alone or in different combinations. Concentration of growth factors are given in Material and Methods. MEM = minimum essential medium; GDF-9 = growth differentiation factor 9; IGF-I = insulin growth factor I; GH = growth hormone. *P $<0.05$ compared to non-cultured ovarian cortex (control); ${ }^{+} \mathrm{P}<0.05$ compared to $\mathrm{MEM}^{+}$(Dunnett test). Values followed by different capital letters differed significantly between culture periods within a given medium; values followed by different lower case letters differed significantly between treatments (SNK test). 

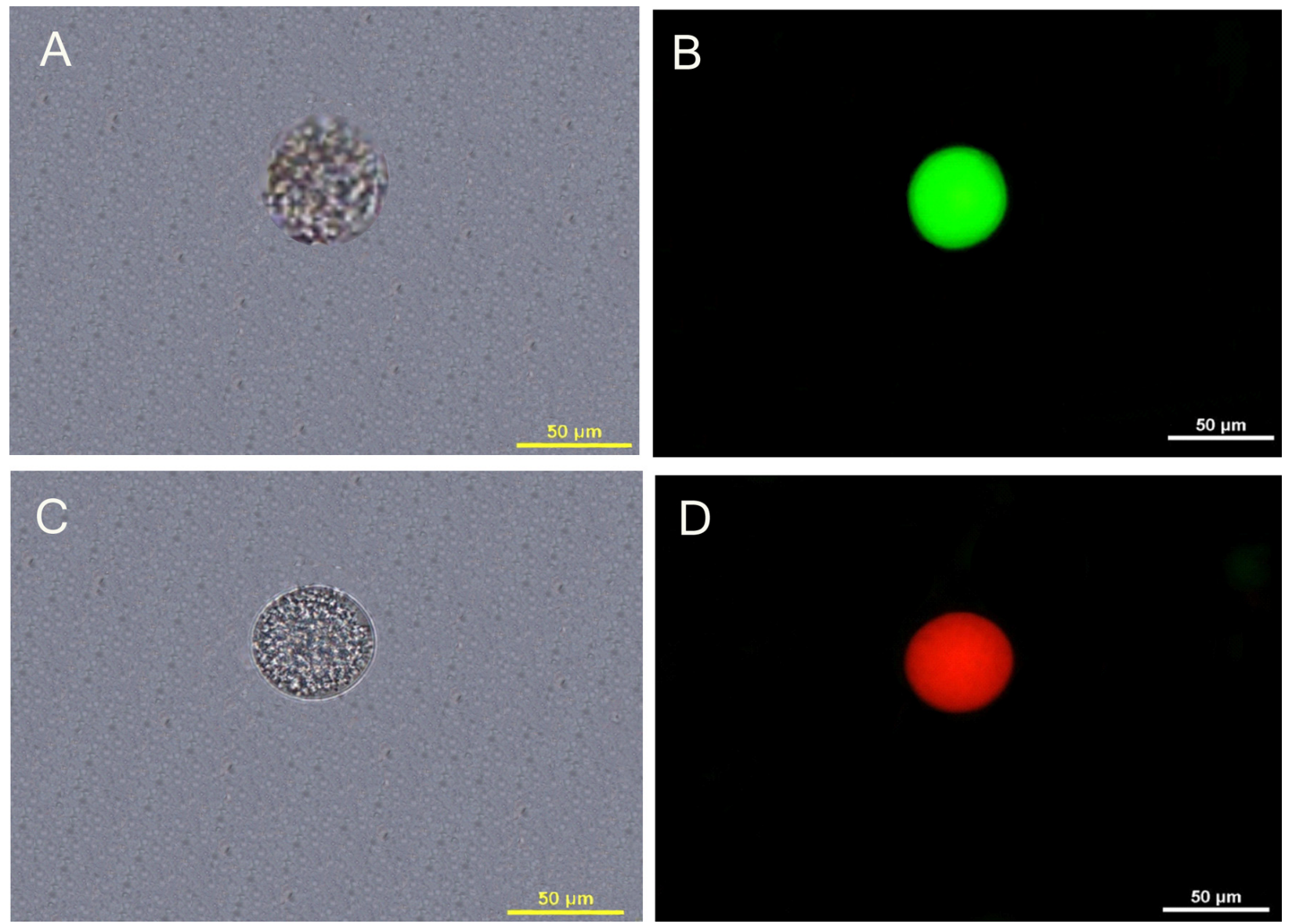

Figure 3. Mechanically isolated follicles visible under a fluorescence microscope after fluorescence staining for follicle viability with calcein-AM ( $A$ and $B$ ) and ethidium homodimer-1 (C and D). Preantral follicles in ovarian tissue cultured in MEM+ containing $50 \mathrm{ng} /$ $\mathrm{mL}$ IGF-I for 7 days were visible by light microscopy ( $A$ and $C$ ) and by fluorescence microscopy ( $B$ and $D)$. MEM = minimum essential medium; IGF-I = insulin growth factor $\mathrm{I}$.

tissue. When compared to $\mathrm{MEM}^{+}$alone, all media tested showed a reduction in the percent of primordial follicles after 1 and 7 days of culture (Figure 4A, $\mathrm{P}<0.05$ ). Regarding the progression of the culture period (from day 1 to 7 ), a significant decrease in the percent of primordial follicles was observed in all media tested except in GDF-9/GH (Figure 4A, $\mathrm{P}<0.05$ ). In contrast, there was a significant and concomitant increase in the percent of intermediate (Figure 4B, $\mathrm{P}<0.05$ ) and primary (Figure $4 \mathrm{C}, \mathrm{P}<0.05$ ) follicles in all treatments tested after 7 days of culture when compared with non-cultured tissue. There was a significant increase in the percent of intermediate follicles cultured for 1 day with IGF-I when compared to $\mathrm{MEM}^{+}$(Figure 4B, P $<0.05)$. After 7 days of culture, the addition of IGF-I/GH to $\mathrm{MEM}^{+}$increased the percent of intermediate follicles when compared to $\mathrm{MEM}^{+}$alone and the other media tested (Figure $4 \mathrm{~B}, \mathrm{P}<0.05)$. With the progression of the culture period, the addition of IGF-I to the culture medium promoted a decrease in the percent of intermediate follicles, while IGF-
$\mathrm{I} / \mathrm{GH}$ increased the rates of intermediate follicles (Figure $4 \mathrm{~B}, \mathrm{P}<0.05)$. After 1 day of culture, all media showed an

Table 1. Percent of viable preantral follicles (stained with calceinAM) after 7 days of in vitro culture.

\begin{tabular}{lc}
\hline Culture medium & Percent \\
\hline MEM $^{+}$ & $91.1 \%$ \\
MEM $^{+}$plus GDF-9 & $91.0 \%$ \\
MEM $^{+}$plus IGF-I & $93.0 \%$ \\
MEM $^{+}$plus GH & $92.4 \%$ \\
MEM $^{+}$plus GDF-9/IGF-I & $93.1 \%$ \\
MEM $^{+}$plus GDF-9/GH & $92.1 \%$ \\
MEM $^{+}$plus IGF-I/GH & $92.0 \%$ \\
MEM $^{+}$plus GDF-9/IGF-I/GH & $91.1 \%$ \\
\hline
\end{tabular}

MEM = minimum essential medium; GDF-9 = growth differentiation factor 9; IGF-I = insulin growth factor I; GH = growth hormone. A total of 1950 follicles were counted. 
increase in the percent of primary follicles when compared with non-cultured tissue, except when GH and GDF-9/IGF-I were used (Figure $4 \mathrm{C}, \mathrm{P}<0.05$ ). The percent of primary follicles cultured after 7 days in medium containing IGF-I was similar to that observed in medium containing GDF-9 $(P>0.05)$ and higher compared to the other treatments
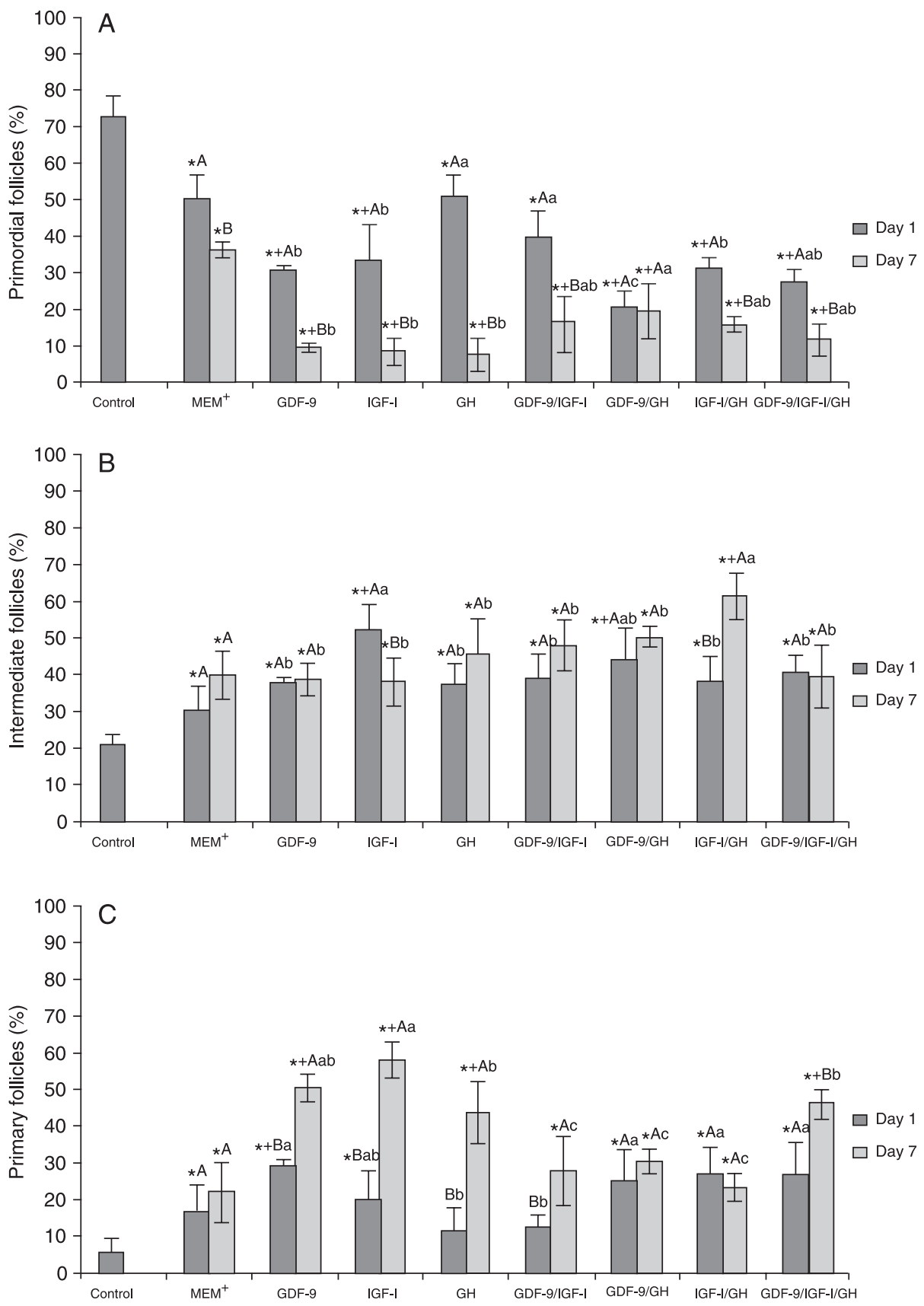

Figure 4. Percent of primordial (A), intermediate (B) and primary (C) follicles in non-cultured tissue (control) and in tissue cultured for 1 and 7 days in MEM ${ }^{+}$and MEM ${ }^{+}$plus GDF-9, IGF-I and GH alone or combined. MEM = minimum essential medium; GDF-9 = growth differentiation factor 9; IGF-I = insulin growth factor I; GH = growth hormone. Concentration of growth factors are given in Material and Methods. ${ }^{*} \mathrm{P}<0.05$ compared to non-cultured ovarian cortex (control). ${ }^{+} \mathrm{P}<0.05$ compared to $\mathrm{MEM}^{+}$(Dunnett test). Values followed by different capital letters differed significantly between culture periods within a given medium; values followed by different lower case letters differed significantly between treatments (SNK test). 
Table 2. Oocyte and follicle diameter in non-cultured tissues (fresh control) and in tissue cultured for 7 days in $\mathrm{MEM}^{+}$(control medium) and MEM+ ${ }^{+}$supplemented with GDF-9, IGF-I and GH alone or in different combinations.

\begin{tabular}{|c|c|c|c|c|}
\hline & \multicolumn{2}{|c|}{ Oocyte diameter $(\mu \mathrm{m})$} & \multicolumn{2}{|c|}{ Follicle diameter $(\mu \mathrm{m})$} \\
\hline & Day 1 & Day 7 & Day 1 & Day 7 \\
\hline Non-cultured & \multicolumn{2}{|c|}{$41.7 \pm 1.9$} & \multicolumn{2}{|c|}{$50.1 \pm 4.4$} \\
\hline $\mathrm{MEM}^{+}$ & $40.7 \pm 3.5^{\mathrm{A}}$ & $43.1 \pm 4.6^{\mathrm{A}}$ & $54.5 \pm 2.8^{\mathrm{A}}$ & $55.8 \pm 4.2^{A}$ \\
\hline $\mathrm{MEM}^{+}$plus GDF & $52.1 \pm 2.5^{\star+A}$ & $53.8 \pm 4.4^{*+\mathrm{A}}$ & $61.2 \pm 3.0^{*+B}$ & $67.1 \pm 2.8^{*+\mathrm{A}}$ \\
\hline $\mathrm{MEM}^{+}$plus IGF & $50.7 \pm 2.7^{\star+A}$ & $53.6 \pm 4.6^{*+\mathrm{A}}$ & $62.3 \pm 2.3^{*+B}$ & $69.6 \pm 2.1^{*+A}$ \\
\hline $\mathrm{MEM}^{+}$plus GH & $55.1 \pm 3.5^{\star+A}$ & $56.8 \pm 4.4^{*+\mathrm{A}}$ & $63.2 \pm 3.0^{*+B}$ & $68.1 \pm 2.0^{*+\mathrm{A}}$ \\
\hline $\mathrm{MEM}^{+}$plus GDF/IGF & $54.1 \pm 3.5^{\star+A}$ & $55.8 \pm 3.4^{\star+A}$ & $61.2 \pm 3.2^{*+B}$ & $67.1 \pm 2.8^{*+\mathrm{A}}$ \\
\hline $\mathrm{MEM}^{+}$plus GDF/GH & $53.1 \pm 2.8^{*+\mathrm{A}}$ & $54.8 \pm 2.8^{*+\mathrm{A}}$ & $60.2 \pm 2.8^{\star+B}$ & $66.1 \pm 2.7^{*+\mathrm{A}}$ \\
\hline $\mathrm{MEM}^{+}$plus IGF/GH & $50.1 \pm 3.1^{*+\mathrm{A}}$ & $51.8 \pm 4.1^{*+\mathrm{A}}$ & $62.2 \pm 3.1^{*+B}$ & $68.1 \pm 3.1^{*+\mathrm{A}}$ \\
\hline $\mathrm{MEM}^{+}$plus GDF/IGF/GH & $49.1 \pm 2.7^{\star+A}$ & $53.8 \pm 4.8^{*+\mathrm{A}}$ & $60.9 \pm 3.9^{*+B}$ & $66.1 \pm 2.6^{*+A}$ \\
\hline
\end{tabular}

Data are reported as means \pm SD for oocyte and follicle diameter. Concentration of growth factors and explanation of $\mathrm{MEM}^{+}$are given in Material and Methods. MEM = minimum essential medium; GDF-9 = growth differentiation factor 9; IGF-I = insulin growth factor I; GH = growth hormone. ${ }^{*} \mathrm{P}<0.05$ compared to non-cultured tissue; ${ }^{+} \mathrm{P}<0.001$ compared to $\mathrm{MEM}^{+}$(Dunnett test). Values followed by different letters differed significantly between culture periods within a given medium ( $P<0.05$; SNK test). A total of 30 follicles were evaluated for each treatment.

(Figure $4 \mathrm{C}, \mathrm{P}<0.05$ ). With the progression of the culture period from 1 to 7 days, the percent of primary follicles was significantly increased in all media tested, except in $\mathrm{MEM}^{+}$alone and $\mathrm{MEM}^{+}$plus GDF-9/GH and IGF-I/GH (Figure $4 \mathrm{C}, \mathrm{P}<0.05$ ). The percent of secondary follicles was not compared due to an insufficient number of follicles for statistical analysis.

After 1 and 7 days of culture, the addition of GDF-9, IGF-I and $\mathrm{GH}$ alone or in different combinations to $\mathrm{MEM}^{+}$ promoted a significant increase in the follicular diameter of unilaminar follicles, i.e., primordial, intermediate and primary follicles together, when compared to non-cultured tissue and $\mathrm{MEM}^{+}$alone (Table 2, $\mathrm{P}<0.05$ ), without differences between treatments $(P>0.05)$. With the progression of the culture period, a significant increase in follicular diameter was observed in all treatments tested, except $\mathrm{MEM}^{+}$alone (Table 2, $\mathrm{P}<0.05$ ).

\section{Discussion}

The present study demonstrated for the first time the effects of GDF-9, IGF-I and GH in different combinations on goat preantral follicle survival, activation and growth during 7 days of culture. Moreover, the viability of preantral follicles obtained from cultured ovarian tissue, was confirmed in all treatments over the course of 7 days by fluorescence analysis. The concentrations used in this experiment were chosen on the basis of the best results obtained by our group using a dose-dependent curve. In the present study, we observed a significant effect of GDF-9, IGF-I and GH alone or combined, enhancing the survival of goat preantral follicles, except when GDF-9/IGF-I and GDF-9/GH were used, since there was no synergistic effect between these compounds when combined. Orisaka et al. (28) suggested that GDF-9 promotes follicular survival and growth during the preantral to early antral transition by suppressing granulosa cell apoptosis and follicular atresia. Deletion of the GDF-9 gene in mice blocked folliculogenesis at the primary stage, demonstrating the importance of this growth factor in early follicular development (29). Subsequent studies have shown that treatment with GDF-9 stimulates granulosa cell proliferation in rats (9), preantral follicle growth in humans (30) and goats (11) and cumulus cell expansion in humans (31) and results in a higher proportion of viable human follicles in organ culture, suggesting a possible role for GDF-9 in follicular survival (10). Moreover, the presence of GDF-9 in primary and later-stage goat follicles (32) suggests that GDF-9-mediated signaling events may be important for the development of preantral follicles in this species. In the current study, after 1 and 7 days of culture, we observed a greater follicular activation (i.e., the transition from primordial to intermediate follicles) with all tested treatments compared to control. Follicular activation in $\mathrm{MEM}^{+}$probably occurred because this medium is enhanced with nutrients such as amino acids and carbohydrates (33). However, in our culture conditions, an elevated activation was observed after the addition of IGF/GH to the culture medium. Follicular activation has been obtained in previous studies in goats (11), cows $(34,35)$ and baboons $(36)$, in which the number of primordial follicles was dramatically reduced, 
with a concomitant increase in the number of developing follicles after in vitro culture of ovarian tissue. Studies have demonstrated that $\mathrm{GH}$ stimulates the production of IGF-I and its messenger RNA (mRNA) in porcine granulosa cells and rat ovary (37). Using human recombinant $\mathrm{GH}$, in vitro studies with mouse follicles have shown that $\mathrm{GH}$ plays an important role in controlling the earlier phases of follicular development because of its stimulatory effect on secondary follicle formation in vitro (15). Likewise, Zhao et al. (14) detected a similar growth promoting effect of IGF-I on rat preantral follicle development when bovine $\mathrm{GH}$ was added to the culture medium at concentrations of 1,10 , or $100 \mathrm{ng} / \mathrm{mL}$. Nevertheless, in the present study, the highest percent of primary follicles was observed with IGF-I alone. This increase may have resulted from the transition of intermediate to primary follicles. Alternatively, IGF-I may have improved survival of the pre-existing primary follicles. This would agree with previous studies that have shown that IGF-I is able to suppress apoptotic DNA fragmentation in cultured rat preantral follicles, acting as an antiatretic factor (38).

In the present study, the number of secondary follicles in non-cultured and cultured goat ovarian tissue contained a low (often zero) and variable number of secondary follicles (data not shown), thereby preventing meaningful analysis. A similar conclusion was drawn for the lack of changes in the secondary follicle population in cultured bovine (34) and baboon (36) ovarian cortical tissue. Nilsson and Skinner (8) and Martins et al. (11) showed that GDF-9 may influence primary follicle progression to secondary follicles in rats and goats, respectively. Although there was the highest increase in the percent of intermediate follicles with IGF-I/GH and of primary follicles with IGF-I, no differences in follicular or

\section{References}

1. Picton HM, Harris SE, Muruvi W, Chambers EL. The in vitro growth and maturation of follicles. Reproduction 2008; 136: 703-715.

2. O'Brien MJ, Pendola JK, Eppig JJ. A revised protocol for in vitro development of mouse oocytes from primordial follicles dramatically improves their developmental competence. Biol Reprod 2003; 68: 1682-1686.

3. Webb R, Garnsworthy PC, Gong JG, Armstrong DG. Control of follicular growth: local interactions and nutritional influences. J Anim Sci 2004; 82 (E-Suppl): E63-E74.

4. McGrath SA, Esquela AF, Lee SJ. Oocyte-specific expression of growth/differentiation factor-9. Mol Endocrinol 1995; 9: 131-136.

5. Hayashi M, McGee EA, Min G, Klein C, Rose UM, van Duin $M$, et al. Recombinant growth differentiation factor-9 (GDF9) enhances growth and differentiation of cultured early ovarian follicles. Endocrinology 1999; 140: 1236-1244.

6. Jaatinen R, Laitinen MP, Vuojolainen K, Aaltonen J, Louhio $H$, Heikinheimo $K$, et al. Localization of growth differentiation factor-9 (GDF-9) mRNA and protein in rat ovaries and cDNA oocyte diameter were observed between treatments. It is possible that intermediate or primary follicles were already large, so that we did not observe an increase in diameter, but only changes in granulosa cell morphology from flattened to cuboidal. Studies have shown that oocyte growth is often insufficient or even undetectable and the development of a thecal cell layer at the preantral stage is rarely observed (39). An increasing list of growth factors has been implicated in regulating the primordial to primary follicle transition and the progression of early preantral follicle development. GDF-9, IGF-I and GH have all been demonstrated to be involved in the orderly progression of follicles through the early stages of preantral development.

GDF-9, IGF-I and GH, each added separately to the culture medium, were able to enhance follicular viability, growth and progression of primordial follicles to primary follicles after 7 days of in vitro culture. Moreover, the addition of IGF-I/GH was more effective in promoting the transition from primordial to intermediate follicles, and the addition of IGF-I alone promoted the highest rates of primary follicles after 7 days of culture. Another set of experiments will be necessary to improve the understanding of the combined action of growth factors that control the orderly progression of follicle development.

\section{Acknowledgments}

The authors thank José Leandro da Silva Neto for technical support in classical histology and all the members of the LAMOFOPA, whose help and enthusiasm made this study possible. Research supported by CNPq (RENORBIO). F.S. Martins is the recipient of a grant from CAPES.

cloning of rat GDF-9 and its novel homolog GDF-9B. Mol Cell Endocrinol 1999; 156: 189-193.

7. Aaltonen J, Laitinen MP, Vuojolainen K, Jaatinen R, HorelliKuitunen N, Seppa L, et al. Human growth differentiation factor 9 (GDF-9) and its novel homolog GDF-9B are expressed in oocytes during early folliculogenesis. J Clin Endocrinol Metab 1999; 84: 2744-2750.

8. Nilsson EE, Skinner MK. Growth and differentiation factor-9 stimulates progression of early primary but not primordial rat ovarian follicle development. Biol Reprod 2002; 67: 10181024.

9. Vitt UA, Hayashi M, Klein C, Hsueh AJ. Growth differentiation factor-9 stimulates proliferation but suppresses the follicle-stimulating hormone-induced differentiation of cultured granulosa cells from small antral and preovulatory rat follicles. Biol Reprod 2000; 62: 370-377.

10. Hreinsson JG, Scott JE, Rasmussen C, Swahn ML, Hsueh AJ, Hovatta O. Growth differentiation factor-9 promotes the growth, development, and survival of human ovarian follicles in organ culture. J Clin Endocrinol Metab 2002; 87: 
316-321.

11. Martins FS, Celestino JJ, Saraiva MV, Matos MH, Bruno JB, Rocha-Junior CM, et al. Growth and differentiation factor-9 stimulates activation of goat primordial follicles in vitro and their progression to secondary follicles. Reprod Fertil Dev 2008; 20: 916-924

12. Louhio H, Hovatta O, Sjoberg J, Tuuri T. The effects of insulin, and insulin-like growth factors I and II on human ovarian follicles in long-term culture. Mol Hum Reprod 2000; 6: 694698.

13. Gutierrez CG, Ralph JH, Telfer EE, Wilmut I, Webb R. Growth and antrum formation of bovine preantral follicles in long-term culture in vitro. Biol Reprod 2000; 62: 13221328.

14. Zhao J, Tavene MAM, Van der Weijden GC, Bevers MM, Van Den Hurk R. Insulin-like growth factor-I (IGF-I) stimulates the development of cultured rat pre-antral follicles. Mol Reprod Develop 2001; 58: 287-296.

15. Liu X, Andoh K, Yokota H, Kobayashi J, Abe Y, Yamada K, et al. Effects of growth hormone, activin, and follistatin on the development of preantral follicle from immature female mice. Endocrinology 1998; 139: 2342-2347.

16. Zhou $\mathrm{H}$, Zhang Y. Effect of growth factors on in vitro development of caprine preantral follicle oocytes. Anim Reprod Sci 2005; 90: 265-272.

17. Hull KL, Harvey S. GH as a co-gonadotropin: the relevance of correlative changes in $\mathrm{GH}$ secretion and reproductive state. J Endocrinol 2002; 172: 1-19.

18. Kumar TR, Wang Y, Lu N, Matzuk MM. Follicle stimulating hormone is required for ovarian follicle maturation but not male fertility. Nat Genet 1997; 15: 201-204.

19. Kobayashi J, Mizunuma H, Kikuchi N, Liu X, Andoh K, Abe $Y$, et al. Morphological assessment of the effect of growth hormone on preantral follicles from 11-day-old mice in an in vitro culture system. Biochem Biophys Res Commun 2000; 268: 36-41.

20. Hull KL, Harvey S. Growth hormone: roles in female reproduction. J Endocrinol 2001; 168: 1-23.

21. Jia XC, Kalmijn J, Hsueh AJ. Growth hormone enhances follicle-stimulating hormone-induced differentiation of cultured rat granulosa cells. Endocrinology 1986; 118: 1401-1409.

22. Langhout DJ, Spicer LJ, Geisert RD. Development of a culture system for bovine granulosa cells: effects of growth hormone, estradiol, and gonadotropins on cell proliferation, steroidogenesis, and protein synthesis. J Anim Sci 1991; 69: 3321-3334.

23. Hong $\mathrm{H}$, Herington $A C$. Differentiation between the effects of IGF-1 and GH on PMSG-induced progesterone production by rat granulosa cells. Growth Regul 1991; 1: 65-71.

24. Andrade LP, Rhind SM, Wright IA, McMillen SR, Goddard PJ, Bramley TA. Effects of bovine somatotrophin (bST) on ovarian function in post-partum beef cows. Reprod Fertil Dev 1996; 8: 951-960.

25. Silva JR, Lucci CM, Carvalho FC, Bao SN, Costa SH,
Santos RR, et al. Effect of coconut water and Braun-Collins solutions at different temperatures and incubation times on the morphology of goat preantral follicles preserved in vitro. Theriogenology 2000; 54: 809-822.

26. Lucci CM, Amorim CA, Rodrigues AP, Figueiredo JR, Bao SN, Silva JR, et al. Study of preantral follicle population in situ and after mechanical isolation from caprine ovaries at different reproductive stages. Anim Reprod Sci 1999; 56: 223-236.

27. Steel RGD, Torrie JH, Dickey DA. Principles and procedures of statistics: a biometrical approach. 3nd edn. New York, McGraw-Hill; 1997.

28. Orisaka M, Orisaka S, Jiang JY, Craig J, Wang Y, Kotsuji F, et al. Growth differentiation factor 9 is antiapoptotic during follicular development from preantral to early antral stage. Mol Endocrinol 2006; 20: 2456-2468.

29. Dong J, Albertini DF, Nishimori K, Kumar TR, Lu N, Matzuk MM. Growth differentiation factor-9 is required during early ovarian folliculogenesis. Nature 1996; 383: 531-535.

30. Elvin JA, Yan C, Matzuk MM. Oocyte-expressed TGF-beta superfamily members in female fertility. Mol Cell Endocrinol 2000; 159: 1-5.

31. Elvin JA, Clark AT, Wang P, Wolfman NM, Matzuk MM. Paracrine actions of growth differentiation factor-9 in the mammalian ovary. Mol Endocrinol 1999; 13: 1035-1048.

32. Silva JR, Van Den Hurk R, van Tol HT, Roelen BA, Figueiredo JR. Expression of growth differentiation factor 9 (GDF9), bone morphogenetic protein 15 (BMP15), and BMP receptors in the ovaries of goats. Mol Reprod Dev 2005; 70: 1119.

33. van Wezel I, Rodgers RJ. Morphological characterization of bovine primordial follicles and their environment in vivo. Biol Reprod 1996; 55: 1003-1011.

34. Wandji SA, Eppig JJ, Fortune JE. FSH and growth factors affect the growth and endocrine function in vitro of granulosa cells of bovine preantral follicles. Theriogenology 1996; 45: 817-832.

35. Braw-Tal R, Yossefi S. Studies in vivo and in vitro on the initiation of follicle growth in the bovine ovary. J Reprod Fertil 1997; 109: 165-171.

36. Fortune JE, Kito S, Wandji SA, Srsen V. Activation of bovine and baboon primordial follicles in vitro. Theriogenology 1998; 49: 441-449.

37. Hynes MA, Van Wyk JJ, Brooks PJ, D’Ercole AJ, Jansen M, Lund PK. Growth hormone dependence of somatomedin-C/ insulin-like growth factor-I and insulin-like growth factor-II messenger ribonucleic acids. Mol Endocrinol 1987; 1: 233242.

38. Chun SY, Billig H, Tilly JL, Furuta I, Tsafriri A, Hsueh AJ. Gonadotropin suppression of apoptosis in cultured preovulatory follicles: mediatory role of endogenous insulin-like growth factor I. Endocrinology 1994; 135: 1845-1853.

39. Smitz JE, Cortvrindt RG. The earliest stages of folliculogenesis in vitro. Reproduction 2002; 123: 185-202. 